\title{
ANALISIS PENERAPAN BALANCED SCORECARD SEBAGAI ALAT UKUR PENILAIAN KINERJA PADA UPT. PUSKESMAS LEGUNG
}

\author{
Wilda Maritha Sari ${ }^{1}$, Astri Furqani ${ }^{2}$ \\ ${ }^{1,2)}$ Fakultas Ekonomi dan Bisnis Universitas Wiraraja \\ Email: wildatoil560@gmail.com ${ }^{1}$, astri@wiraraja.ac.id $^{2}$
}

\begin{abstract}
ABSTRAK
Peneliti ini bertujuan untuk mengetahui Analisis Penerapan Balanced Scorecard Sebagai Alat Ukur Penilaian Kinerja Pada UPT. Puskesmas Legung. Peneliti menggunakan metode penelitian kuantitatif. Sampel dalam penelitian ini adalah puskesmas legung. Untuk pengumpulan data menggunakan observasi, dokumentasi dan wawancara. Teknik analisis yang digunakan yaitu analisis deskriptif dengan mendeskripsikan data yang telah terkumpul. Pendeskripsian data ini dilakukan dengan mengukur kinerja dari masing-masing perspektif dalam balanced scorecard yaitu perspektif keuangan, perspektif pelanggan, perspektif proses bisnis internal, perspektif pembelajaran dan pertumbuhan. Dari keempat perspektif tersebut menyatakan bahwa proses bisnis internal merupakan perspektif yang rata-ratanya lebih paling menonjol. Hasil penelitian menunjukkan bahwa dari ke empat perspektif dalam balanced scorecard UPT. Puskesmas Legung sudah melakukan kinerja yang baik yaitu $68 \%$ yang berada dikisaran point $60 \%-80 \%$. Sehingga Penerapan Balanced Scorecard sudah dilakukan dengan sempurna.
\end{abstract}

Kata Kunci : Kinerja Puskesmas, Balanced Scorecard

\section{INTRODUCTION}

Berukurnya kemampuan sudah menjadi berita populer di berbagai negara berkembang. Perusahaan lokal dan antarbangsa berjuang untuk menjadi yang terbaik dalam menciptakan suasana yang baik. Sebagian ini berukurnya kemampuan identik dilaksanakan secara modern dan saja bertumpu pada bagian nonfinansial atau finansial. Bagi menjawab cela ini, maka diperoleh berapa cara pendekatan untuk mengukur kemampuan industri untuk memandang empat perspektif yakni pespektif bukan keuangan finansial, perspektif pelanggan, perpsektif proses bisnis internal, serta perspektif pembelajaran dan pertumbuhan. Maka bagi menyamakan bentuk bagian finansial dengan non bagian finansial menghasilkan suatu balanced scorecard.

Rancangan di bagian kesehatan sudah ditetapkan Visi dan Misi pembangunan kesehatan pada UPT. Puskesmas Legung, sebagaimana ditetapkan sebagai visi Dinas Kesehatan Puskesmas Legung, "Puskesmas Legung Super Mantap ( Sumenep Sejahtera dengan pemerintah yang bersih dan mandiri, agamis, 
nasionalis, transparan, adil dan profesional)". Misi yang ingin dicapai melalui Pembangunan Kesehatan tersebut adalah: Memperdayakan masyarakat untuk hidup sehat dan mandiri. Memberikan Pelayanan yang bermutu.

Puskesmas dipertegas agar bisa memberikan layanan yang terhadap pasien, profesional dengan harga bersaing sehingga strategi dan kemampuan puskesmas itu harus berorientasi pada keinginan masyarakat. Oleh sebaba itu, dibutuhkan alat ukur dengan Balanced Scorecard (BSC) yang berharap bisa menjawab tuntutan dan tantangan zaman di masa yang akan datang.

Balanced scorecard merupakan tindakan yang baik dalam mengukur kemampuan baik dari aspek keuangan maupun finansial dan bukan keuangan.. Dengan rumusan masalah Bagaimana kinerja keuangan UPT. Puskesmas Legung jika diukur menggunakan penerapan Balanced Scorecardbaik dari perspektif keuangan, perspektif pelanggan, proses bisnis internal serta pembelajaran dan pertumbuhan. serta bertujuan bagi mengetahui kemampuan keuangan UPT. Puskesmas Legung jika diukur menggunakan penerapan Balanced Scorecard baik bagi perspektif keuangan, perspektif pelanggan, proses bisnis internal serta pembelajaran dan pertumbuhan.

\section{A. Definisi Kinerja dan Pengukuran Kinerja}

Menurut Sucipto (dalam Yuangga, 2017:14) pengertian kinerja keuangan adalah penentuan ukuranukuran tertentu yang dapat mengukur keberhasilan suatu organisasi atau perusahaan dalam menghasilkan laba.

\section{B. Penilaian Kinerja pada Organisasi} Sektor Publik

Pengukuran kemampuan area komunitas dilakukan bagi meluruskan kemampuan negara, pembagian akar kapasitas beserta pembentukan dekrit, bersama meluruskan hubungan konsumen.

\section{Pengertian Balanced Scorecard}

Balanced Scorecard ialah salah esa gawai tata laksana yang menduga benar mendukung belacak industri berarti melaksanakan cetak biru bidang usaha.

\section{Kerangka Pikir}

Mengenai kondisi akal berarti eksplorasi ini diilustrasikan bagai beserta:

Pengukuran Kemampuan Puskesmas beserta Balanced Scorecard
a. Perspektif Keuangan
b. Perspektif Pelanggan
c. Perspektif Proses Bisnis Internal
d. Perspektif Pertumbuhan dan Pembelajaran

\section{LITERATURE REVIEW}

Gambar 2.3 Kerangka Pikir 
3) Rasio Efektifitas

\section{METHODS}

\section{A. Jenis Penelitian}

Eksplorasi ini memerlukan investigasi kuantitatif beserta ancangan deskriptif ialah beserta pengumpulan data primer.

\section{B. Tempat dan Waktu Penelitian}

Eksplorasi ini akan dibagaikan di UPT. Puskesmas Legung yang terwalak di wilayah Kecamatan Batang-Batang. Diawali dari bulan Februari sampai dengan bulan Juni (Sampai selesainya penelitian ini).

\section{Sampel dan Populasi}

Populasi berarti observasi ini ialah Puskesmas Legung. Penarikan sampel berarti observasi ini dilakukan dengan Purposive Sampling.

\section{Jenis beserta Sumber Data Penelitian}

Atas eksplorasi ini memakai jenis data kuantitatif. Cukupkan asal data yang difungsikan atas penelitian ini ialah data primer.

\section{E. Teknik Pengumpulan Data}

Observasi, teknik pengumpulan data beserta cara melakukan pengamatan langsung; Dokumentasi bisa dilakukan beserta cara mencatat ulang, memotret, fotocopy laporan keuangan tahun 20152019; Wawancara, digunakan bagi informal.

\section{F. Teknik Analisis Data}

a. Kinerja Perspektif Keuangan

1) Rasio Ekonomis

$$
\begin{aligned}
& \text { Rasio Ekonomis = } \\
& \frac{\text { Realigasi Pengeluaran }}{\text { Anggaran Pengeluaran }} \times 100 \%
\end{aligned}
$$

2) Rasio Efisiensi

$$
\begin{aligned}
& \text { Rasio Efisiensi } \\
& \frac{\text { Realisasi Belanja }}{\text { Realisasi Pendapatan }} \times 100 \%
\end{aligned}
$$

\section{Rasio Efektifitas= $\frac{\text { Realisasi Pendapatan }}{\text { Anggaran Pendapatan }} \times 100 \%$}

b. Kinerja Perspektif Pelanggan

1. Jumlah Pelanggan

a). Retensi Pelanggan

b). Akuisisi Pelanggan.

c. Kinerja Perspektif Proses Bisnis Internal

1. Proses Inovasi

2. Proses Operasi

a. Total Lawatan Rawat Jalan

Data diproses dari banyaknya total lawatan rawat jalan di UPT. Puskesmas Legung.

b. Total Lawatan Rawat Inap

1) $\operatorname{ALOS}$ (Average Lenght of Stay) $=$ $\underline{\text { Tot.Hari pemeliahraan Penderita Keluar }}$ Total penderita keluar (hidup+mati)

2) $\mathrm{BOR}=$ $\frac{\text { Total Hari Perawatan Rumah Sakit }}{\text { (Total pembaringan Xtotal hari berbagai satuan waktu) }} \times$
$100 \%$

3) $\mathrm{TOI}=$

(Total pembaringanrXTotal hari)-Hari Perawatan RS Total penderita Keluar (Hidup +Mati)

4) BTO (Bed Turn Over Rate $)=$ total penderita Keluar (hidup+mati) total pemvaringan

5) GDR (Gross Death Rate $)=$ $\frac{\text { totalpenderita mati seluruhnya }}{\text { total penderita Keluar (hidup+mati) }} \times$ 1000 
6) NDR (Net Death Rate) = $\frac{\text { total penderita mati } \geq 48 \text { jam }}{\text { total penderita Keluar (hidup+mati) }} \times$ 1000

Kaki Ideal Indikator terkait dengan Pelayanan Puskesmas

\begin{tabular}{|l|l|}
\hline \multicolumn{1}{|c|}{ Indikator } & Standar Ideal \\
\hline ALOS & $6-9$ hari \\
\hline BOR & $1-3$ hari \\
\hline TOI & $\begin{array}{l}40-50 \text { kali } \\
\text { BTO }\end{array}$ \\
\hline GDR & $\begin{array}{l}\text { Tidak Lebih dari } \\
\text { penderita } 1000 \\
\text { keluar }\end{array}$ \\
\hline NDR & $\begin{array}{l}\text { Tidak Lebih dari } \\
25 \text { per } 1000 \\
\text { penderita } \\
\text { keluar }\end{array}$ \\
\hline
\end{tabular}

Sumber: DEPKES RI 2005

e. Kemampuan Perspektif Pertumbuhan dan Pembelaajaran

Produktifitas karyawan yaitu kesetaraan yang dicapai atas guna bergabung energi kerja persatuan waktu (per-jam per-orang).

f. Menentukan Ukuran Kinerja Pada masing-masing Perspektif Balanced Scorecard

Hasil pemberian skor pada masingmasing indikator berbagai keempat perspektif Balanced Scorecard menggunakan perhitungan yang ditetapkan oleh Valva dalam Septianie (2013) sebagai berikut:
Kinerja $=\frac{\text { Total skor }}{\text { Skor maksimal }} \times 100 \%$
a) Sangat baik
$=80 \%-100 \%$
b) Baik
$=60 \%-<80 \%$
c) Cukup
$=40 \%-<60 \%$
d) Tidak baik
$=20 \%-<40 \%$
e) Sangat tidak baik $=0 \%-<20 \%$

\section{RESULTS AND DISCUSSIONS}

A. Hasil Penelitian

a) Laporan Realisasi Anggaran Tahun
2015-2019

\begin{tabular}{|l|l|l|l|l|}
\hline Tahun & $\begin{array}{l}\text { Anggaran } \\
\text { Pendapatan }\end{array}$ & $\begin{array}{l}\text { Realisasi } \\
\text { Pendapatan }\end{array}$ & $\begin{array}{l}\text { Realisasi } \\
\text { Belanja }\end{array}$ & $\begin{array}{l}\text { Anggaran } \\
\text { Belanja }\end{array}$ \\
\hline 2015 & $42,465,450.00$ & $45,106,009.00$ & $31,073,010.00$ & $34,521,518.00$ \\
\hline 2016 & $63,060,625.00$ & $59,819,875.00$ & $3,381,400.00$ & $3,600,000.00$ \\
\hline 2017 & $46,676,675.00$ & $118,082,275.00$ & $62,399,184.00$ & $66,892,474.00$ \\
\hline 2018 & $85,890,925.00$ & $80,349,331.00$ & $25,337,315.00$ & $41,507,441.00$ \\
\hline 2019 & $112,082,216.00$ & $42,610,709.00$ & $37,136,636.00$ & $54,822,479.00$ \\
\hline
\end{tabular}

Sumber: data diolah

Berdasarkan hasil dokumentasi laporan realisasi anggaran pada Puskesmas Legung anggaran setiap tahunnya mengalami peningkatan mulai dari tahun 2015 hingga tahun 2019, karena banyaknya kunjungan pasien.

b) Data Kunjungan Tahun 2015-2019

\begin{tabular}{|c|c|c|c|c|c|c|c|c|}
\hline $\begin{array}{l}\text { Tah } \\
\text { un }\end{array}$ & $\begin{array}{l}\text { Tem } \\
\text { pat } \\
\text { tidur }\end{array}$ & $\begin{array}{l}\text { Hari } \\
\text { Pera } \\
\text { wata } \\
\text { n }\end{array}$ & $\begin{array}{l}\text { Lam } \\
\text { a } \\
\text { dira } \\
\text { wat }\end{array}$ & $\begin{array}{l}\text { pasie } \\
\text { n } \\
\text { Kelu } \\
\text { ar(hi } \\
\text { dup } \\
\text { +ma } \\
\text { ti) }\end{array}$ & $\begin{array}{l}\text { Pasi } \\
\text { en } \\
\text { kelu } \\
\text { ar } \\
\text { mati } \\
\geq 48 \\
\text { jam } \\
\text { dira } \\
\text { wat }\end{array}$ & $\begin{array}{l}\text { Pasien } \\
\text { Lama }\end{array}$ & $\begin{array}{l}\text { Pasi } \\
\text { en } \\
\text { Baru }\end{array}$ & $\begin{array}{l}\text { Total } \\
\text { Kunju } \\
\text { ngan }\end{array}$ \\
\hline 2015 & 12 & 149 & 149 & 73 & 0 & 3100 & 1250 & 4350 \\
\hline
\end{tabular}


Journal of Accounting and Financial Issue

ISSN :

Volume 1, Nomor 2, Oktober 2020

\begin{tabular}{|l|l|l|l|l|l|l|l|l|}
\hline 2016 & 12 & 322 & 322 & 195 & 0 & 2700 & 1726 & 4426 \\
\hline 2017 & 12 & 495 & 495 & 207 & 0 & 3331 & 2054 & 5385 \\
\hline 2018 & 12 & 668 & 668 & 341 & 0 & 1533 & 2503 & 4036 \\
\hline 2019 & 12 & 841 & 841 & 475 & 0 & 2712 & 2713 & 5425 \\
\hline
\end{tabular}

Sumber: Puskesmas Legung

c) Jumlah Karyawan

c. Tahun

$2017=\frac{62,399,184}{66,892,474} \times 100 \%=93.28 \%$

d. Tahun

$2018=\frac{25,337,315}{41_{\imath} 507,441} \times 100 \%=61.04 \%$

e. Tahun

$2019=\frac{37,136,636}{54,822,479} \times 100 \%=67.73 \%$

\section{Jumlah Karyawan UPT. Puskesmas}

\begin{tabular}{|c|c|c|}
\hline Tahun & PNS & Jumlah Karyawan Keluar \\
\hline 2015 & 8 & 2 orang \\
\hline 2016 & 2 & 0 \\
\hline 2017 & 5 & 1 orang \\
\hline 2018 & 3 & 0 \\
\hline 2019 & 10 & $\mathbf{2}$ orang \\
\hline Total & $\mathbf{2 8}$ & \\
\hline
\end{tabular}

Legung

Sumber: Puskesmas Legung

Dilihat dari data total karyawan Puskesmas Legung bahwa total karyawan yang keluar beserta Puskesmas ini dimutasi ke puskesmas lain.

B. Pembahasan

a) Penilaian Kinerja dari Perspektif Keuangan

1) Rasio Ekonomis

$$
\begin{aligned}
& \text { Rasio Ekonomis } \\
& \frac{\text { Realisasi Pengelwaran }}{\text { Anggaran Pengeluaran }} \times 100 \%
\end{aligned}
$$

\section{Perhitungan:}

a. Tahun 2015=

$$
\frac{31,073,010}{34,521,518} \times 100 \%=90.01 \%
$$

b. Tahun

$$
2016=\frac{3,381,400}{3,600,000} \times 100 \%=93.92 \%
$$

\section{Rasio Ekonomis}

\begin{tabular}{|l|l|l|}
\hline & \multicolumn{2}{|c|}{ RASIO EKONOMIS } \\
\hline Tahun 2015 & $90.01 \%$ & Ekonomis \\
\hline Tahun 2016 & $93.92 \%$ & Ekonomis \\
\hline Tahun 2017 & $93.28 \%$ & Ekonomis \\
\hline Tahun 2018 & $61.04 \%$ & Ekonomis \\
\hline Tahun 2019 & $67.73 \%$ & Ekonomis \\
\hline
\end{tabular}

Sumber: data diolah

\section{Grafik Perspektif Keuangan}

Tahun 2015-2019

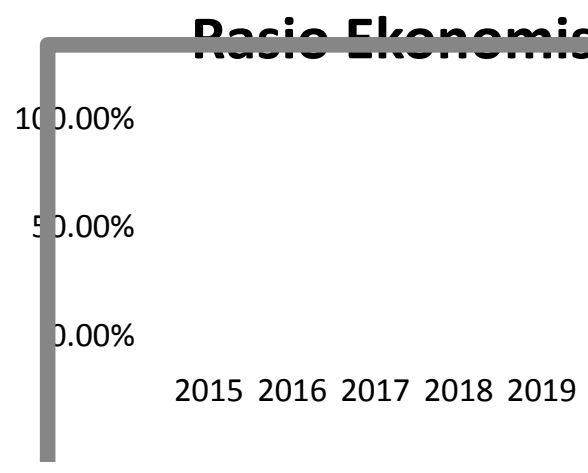

Series 1

2) Rasio Efisiensi

$$
\begin{aligned}
& \text { Rasio Efisiensi } \\
& \frac{\text { Realisasi Belanja }}{\text { Realisasi Pendapatan }} \times 100 \%
\end{aligned}
$$

\section{Perhitungan :}

a. Tahun

$2015=$

$\frac{351_{0}, 733_{3}, 544}{45,106,009} \times 100 \%=779.79 \%$ 
b. Tahun

$2016=$ $\frac{160,791_{2} 571}{59,819,875} \times 100 \%=268.79 \%$

c. Tahun $2017=$ $\frac{140,990,391}{118,082,275} \times 100 \%=119.40 \%$

d. Tahun $2018=$ $\frac{175,977,175}{80,349,331} \times 1100 \%=219.01 \%$

e. Tahun

$2019=$ $\frac{188,591,214}{42,610,709} \times 100 \%=442.59 \%$

Rasio Efisiensi

\begin{tabular}{|c|c|c|}
\hline & \multicolumn{2}{|c|}{ RASIO EFISIENSI } \\
\hline Tahun 2015 & $779.79 \%$ & Tidak Efisien \\
\hline Tahun 2016 & $268.79 \%$ & Tidak Efisien \\
\hline Tahun 2017 & $119.40 \%$ & Tidak Efisien \\
\hline Tahun 2018 & $219.01 \%$ & Tidak Efisien \\
\hline Tahun 2019 & $442.59 \%$ & Tidak Efisien \\
\hline
\end{tabular}

Sumber: diolah peneliti

GrafikPerspektif Keuangan

Tahun 2015-2019

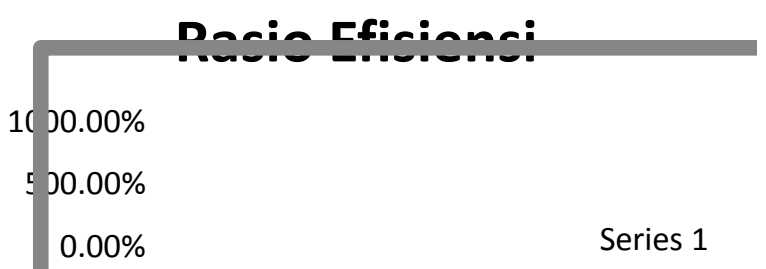

3) Rasio Efektifitas
Rasio
Efektifitas
$\frac{\text { Realisasi Pendapatan }}{\text { Anggaran Pendaptan }} \times 100 \%$

Perhitungan :

$$
\begin{aligned}
\text { a. Tahun } & \\
& 2015 \\
= & \frac{45,106,009}{42,465,450} \times 100 \%=106.21 \%
\end{aligned}
$$

UPT. Puskesmas Legung bukan efektif (106.21\%), yang berarti tingkat pencapaian hasil lebih kecil beserta target yang ditetapkan.

b. Tahun

$$
2016=\frac{59,819,875}{63,060,625} \times 100 \%=94.86 \%
$$

Tahun 2016 yaitu (94.86\%), UPT. Puskesmas Legung adalah Efektif, yang berarti realisasi anggaran puskesmas lebih besar beserta target anggaran puskesmas.

$$
\begin{aligned}
& \text { c. Tahun } \\
& 2017=\frac{118,082,275}{46,676,675} \times 100 \%=252.97 \%
\end{aligned}
$$

UPT. Puskesmas Legung yaitu tidak efektif $(252.97 \%)$

d. Tahun

$$
2018=\frac{80,349,331}{85,890,925} \times 100 \%=93.54 \%
$$

Tahun 2018 yaitu (93.54\%), UPT. Puskesmas Legung iaalah efektif, realisasi anggaran puskesmas hasilnya lebih besar beserta anggaran puskesmas.

$$
\begin{aligned}
& \text { e. Tahun } \\
& 2019= \\
& \frac{42,610,709}{112,082,216} \times 100 \%=38.01 \%
\end{aligned}
$$

Pada tahun 2019 yaitu (38.01\%), UPT. Puskesmas Legung iaalah Efektif, yang berarti realisasi anggaran puskesmas hasilnya lebih tinggi .

\section{Grafik Perspektif Keuangan}

Tahun 2015-2019 


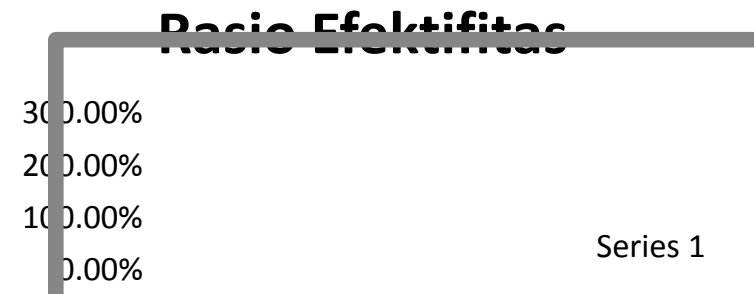

b) Penilaian Kemampuan bagi Perspektif Pelanggan

1. Jumlah Pelanggan

a. Retensi Pelanggan

\begin{tabular}{|l|l|l|l|}
\hline & & & Retensi \\
Tahun & $\begin{array}{l}\text { Pelanggan } \\
\text { Lama (a) }\end{array}$ & $\begin{array}{l}\text { Total } \\
\text { Lawatan } \\
\text { (b) }\end{array}$ & Pelanggan $\left(-\frac{1}{b}\right)$ \\
\hline 2015 & 3100 & 4350 & $71,26 \%$ \\
\hline 2016 & 2700 & 4426 & $61,00 \%$ \\
\hline 2017 & 3331 & 5385 & $61,85 \%$ \\
\hline 2018 & 1533 & 4036 & $37,98 \%$ \\
\hline 2019 & 2712 & 5425 & $49,99 \%$ \\
\hline
\end{tabular}

Sumber: bagian rekam medis UPT. Puskesmas Legung tahun 2015-2019

Retensi pelanggan UPT. Puskesmas Legung menunjukkan bahwa tahun 2015 sampai tahun 2019 mengalami penurunan, karena mampu mempertahankan pelanggan yang ada.

\section{Grafik Retensi Pelanggan}

Tahun 2015-2019

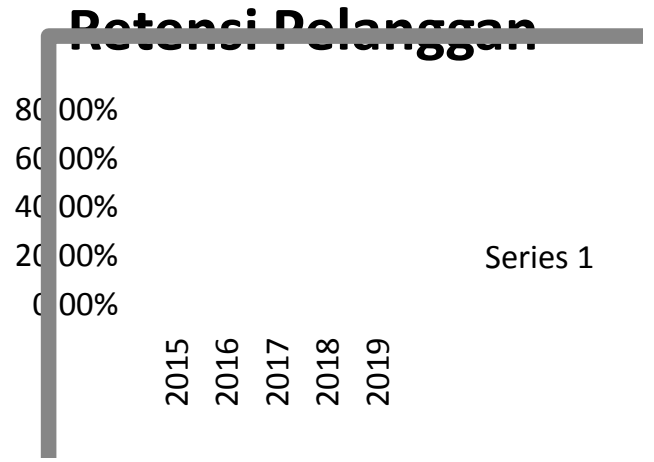

b. Akuisisi Pelanggan

\begin{tabular}{|l|c|l|l|}
\hline & & & \\
Tahun & $\begin{array}{l}\text { Pelanggan Baru } \\
\text { (a) }\end{array}$ & Total Lawatan (b) & Akuisisi Pelanggan $\frac{a}{b}$ \\
\hline 2015 & 1250 & 4350 & $28,73 \%$ \\
\hline 2016 & 1726 & 4426 & $38,99 \%$ \\
\hline 2017 & 2054 & 5385 & $38,14 \%$ \\
\hline 2018 & 2503 & 4036 & $50,00 \%$ \\
\hline 2019 & 2713 & 5425 & \\
\hline
\end{tabular}

Sumber: bagian rekam medis UPT.

Puskesmas Legung tahun 2015-2019

Akuisisi pelanggan UPT. Puskesmas Legung dari 2015 sampai beserta 2019 mengalami peningkatan, karena fasilitas dan pelayanan puskesmas terhadap pasien sesuai beserta prosedur pelayanan.

\section{Grafik Akuisisi Pelanggan}

Tahun 2015-2019 


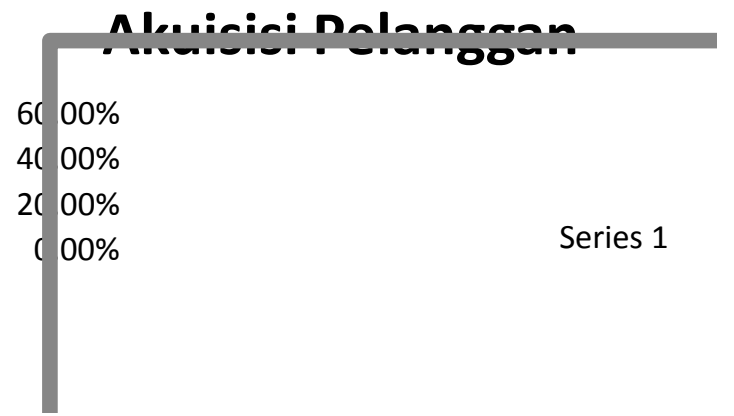

c) Penilaian Kinerja dari Perspektif Proses Bisnis Internal

a. Bagian Inovasi

Semakin berlebihan puskesmas di Indonesia, sewaktu puskesmas semakin memaksakan bagi membentangkan layanan aktual bagi bisa diajukan akan bangsa. Sehingga bersama adanya bagian inovasi ini puskesmas memiliki harapan sangat besar bagi memperoleh bagi penderita yang tinggi besar.

b. Bagian Operasi

1. Total Lawatan Rawat Jalan yang sering berkunjung melakukan tes kesehatan ke puskesmas.
2. Total Lawatan Rawat Inap
Penunjuk Pemakaian Jaga
Ihnap warsa 2015-2019

\begin{tabular}{|c|c|c|c|c|c|c|}
\hline \multirow[b]{2}{*}{ No } & \multirow{2}{*}{$\begin{array}{l}\text { Indikator } \\
\text { Pemanfaatan }\end{array}$} & \multicolumn{5}{|c|}{ Kinerja Rawat Inap Puskesmas } \\
\hline & & $\begin{array}{l}\text { Tahun } \\
2015\end{array}$ & $\begin{array}{l}\text { Tahun } \\
2016\end{array}$ & $\begin{array}{l}\text { Tahun } \\
2017\end{array}$ & $\begin{array}{l}\text { Tahun } \\
2018\end{array}$ & $\begin{array}{l}\text { Tahun } \\
2019\end{array}$ \\
\hline 1 & $\begin{array}{l}\text { Jumlah Hari } \\
\text { Perawatan }\end{array}$ & 149 & 322 & 495 & 668 & 841 \\
\hline 2 & $\begin{array}{l}\text { Jumlah Lama } \\
\text { Perawatan }\end{array}$ & 149 & 322 & 495 & 668 & 841 \\
\hline 3 & $\begin{array}{l}\text { Jumlah Pasien } \\
\text { Keluar }(\mathrm{h}+\mathrm{m})\end{array}$ & 73 & 195 & 207 & 341 & 475 \\
\hline 4 & $\begin{array}{l}\text { PasienKeluar } \\
\text { mati } \geq 48 \text { jam } \\
\text { dirawat }\end{array}$ & 0 & 0 & 0 & 0 & 0 \\
\hline 5 & $\begin{array}{l}\text { Jumlah Tempat } \\
\text { Tidur }\end{array}$ & 12 & 12 & 12 & 12 & 12 \\
\hline 6 & $\begin{array}{l}\text { Totalpelanggan } \\
\text { meninggal }\end{array}$ & 32 & 18 & 12 & 8 & 6 \\
\hline 7 & $\begin{array}{l}\text { Jumlah Hari } \\
\text { Kalender }\end{array}$ & 365 & 365 & 365 & 365 & 365 \\
\hline
\end{tabular}

Sumber: rekam medis UPT. Puskesmas Legung

\begin{tabular}{|c|l|l|l|l|l|}
\hline No. & $\begin{array}{l}\text { Jenis } \\
\text { Lawatan } \\
\text { rawat jalan }\end{array}$ & 2015 & 2016 & 2017 & 20 \\
\hline 1 & $\begin{array}{l}\text { Lawatan } \\
\text { Baru }\end{array}$ & 1250 & 1726 & 2054 & 2503 \\
\hline 2 & $\begin{array}{l}\text { Lawatan } \\
\text { Lama }\end{array}$ & 3100 & 2700 & 3331 & 1533 \\
\hline & $\begin{array}{l}\text { Total } \\
\text { Lawatan }\end{array}$ & 4350 & 4426 & 5385 & 4036 \\
\hline
\end{tabular}

Sumber: bagian rekam medis UPT. Puskesmas Legung tahun 2015-2019

Dilihat bahwa dari tahun 2015 sampai 2019, peningkatan lawatan baru pada rawat jalan, karena beserta lawatan baru penderita yang bukan pernah sama sekali berkunjung melakukan tes kesehatan ke puskesmas. Sedangkan kunjungan lama, dimana pasien
201Tabel Perhitungan Kinerja Rawat Inap UPT. 2713019 .

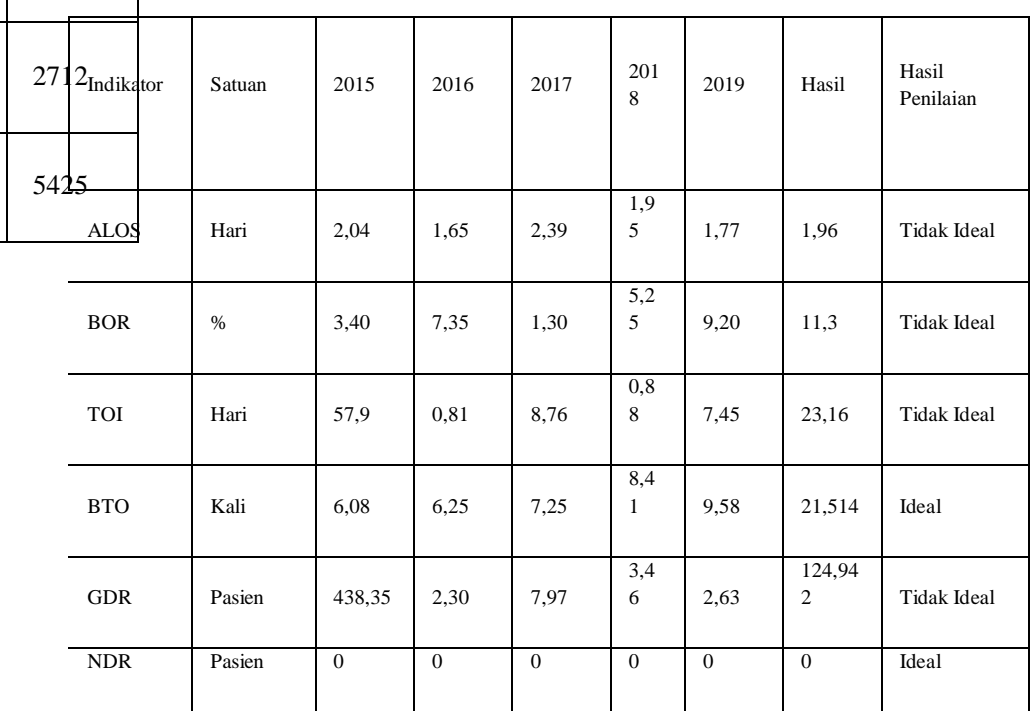

Sumber: diolah peneliti
Puskesmas Legung pada Tahun 2015 sampai 
d) Penilaian Kinerja dari Perspektif Pertumbuhan dan Pembelajaran

1. Produktifitas Karyawan

$$
\begin{aligned}
& \text { Produktifitas karyawan }= \\
& \frac{\text { jumlah Pendapatan }}{\text { Jumlah karyawan }} \times 100 \%
\end{aligned}
$$

\section{Perhitungan:}

$$
\begin{aligned}
& \text { a. Tahun } 2015= \\
& \frac{\text { jumlah Pendapatan }}{\text { Jumlah karyawan }} \times 100 \%= \\
& \frac{45.106 .009}{8}=5.638 .251
\end{aligned}
$$

Pada tahun 2015 mengalami penurunan karena ada sebagian karyawan yang di pindah tugas (mutasi) dari puskesmas tersebut.

$$
\begin{aligned}
& \text { b. Tahun } 2016= \\
& \frac{\text { jumlah Pendapatan }}{\text { Jumlah karyawan }} \times 100 \%= \\
& \frac{59,819,875}{2}=29,909,937
\end{aligned}
$$

Pada tahun 2016 mengalami penurunan karena ada sebagian karyawan yang di pindah tugas (mutasi) dari puskesmas tersebut.

$$
\begin{aligned}
& \text { c. Tahun } 2017= \\
& \frac{\text { jumlah Pendapatan }}{\text { Jumlah karyawan }} \times 100 \%= \\
& \frac{118.082 .275}{5}=23,616,455
\end{aligned}
$$

Pada tahun 2017 mengalami peningkatan yang sangat baik karena karyawan baru sudah mampu mengetahui kelemahan pada puskesmas tersebut.

$$
\begin{aligned}
& \text { d. Tahun } 2018= \\
& \frac{\text { jumlah Pendapatan }}{\text { Jumlah karyawan }} \times 100 \%= \\
& \frac{80,349,331}{3}=26,783,110
\end{aligned}
$$

Pada tahun 2018 mengalami peningkatan yang sangat baik karena karyawan baru mampu mengetahui kelemahan pada puskesmas tersebut. e. Tahun

$2019=$

$$
\begin{aligned}
& \frac{\text { jumlah Pendapatan }}{\text { Jumlah karyawan }} \times 100 \%= \\
& \frac{42,610_{a} 709}{10}=4,261,071
\end{aligned}
$$

Pada tahun 2019 mengalami penurunan yang sangat tinggi dibanding dari tahun 2015 dikarenakan tidak adilnya sistem kompensasi dan tunjuangan.

\section{Grafik Perspektif Pertumbuhan dan Pembelajaran}

Tahun 2015-2019

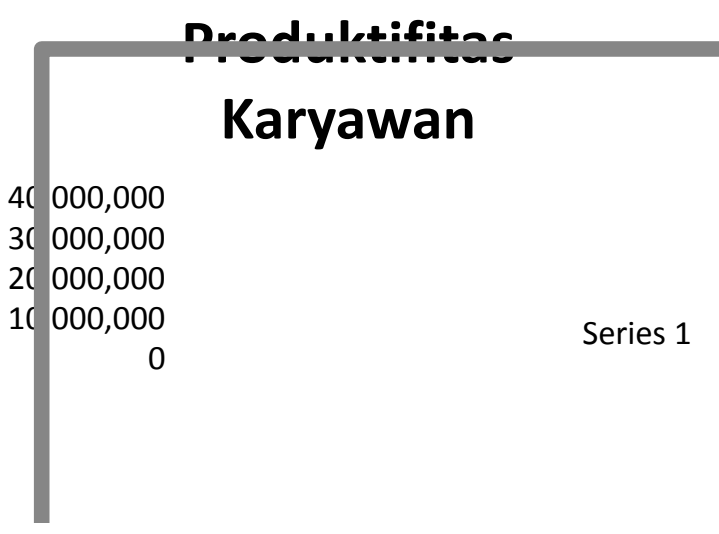

\section{e).Rekapitulasi Skor Penilaian Balanced Scorecard}

Skor Penilaian

\begin{tabular}{|c|l|l|l|}
\hline Faktor & Interval & Kriteria & Nilai \\
\hline Perspektif Keuangan & \multicolumn{3}{|l|}{} \\
\hline 1. Rasio Ekonomis & & & \\
\hline tahun 2015 & $90.01 \%$ & Baik & 3 \\
\hline Tahun 2016 & $93.92 \%$ & Baik & 3 \\
\hline Tahun 2017 & $93.28 \%$ & Baik & 3 \\
\hline Tahun 2018 & $61.04 \%$ & Cukup & 2 \\
\hline Tahun 2019 & $67.73 \%$ & Cukup & 2 \\
\hline & \multicolumn{3}{|c|}{ Skor Maksimal 3 } \\
\hline
\end{tabular}


Journal of Accounting and Financial Issue

ISSN :

Volume 1, Nomor 2, Oktober 2020

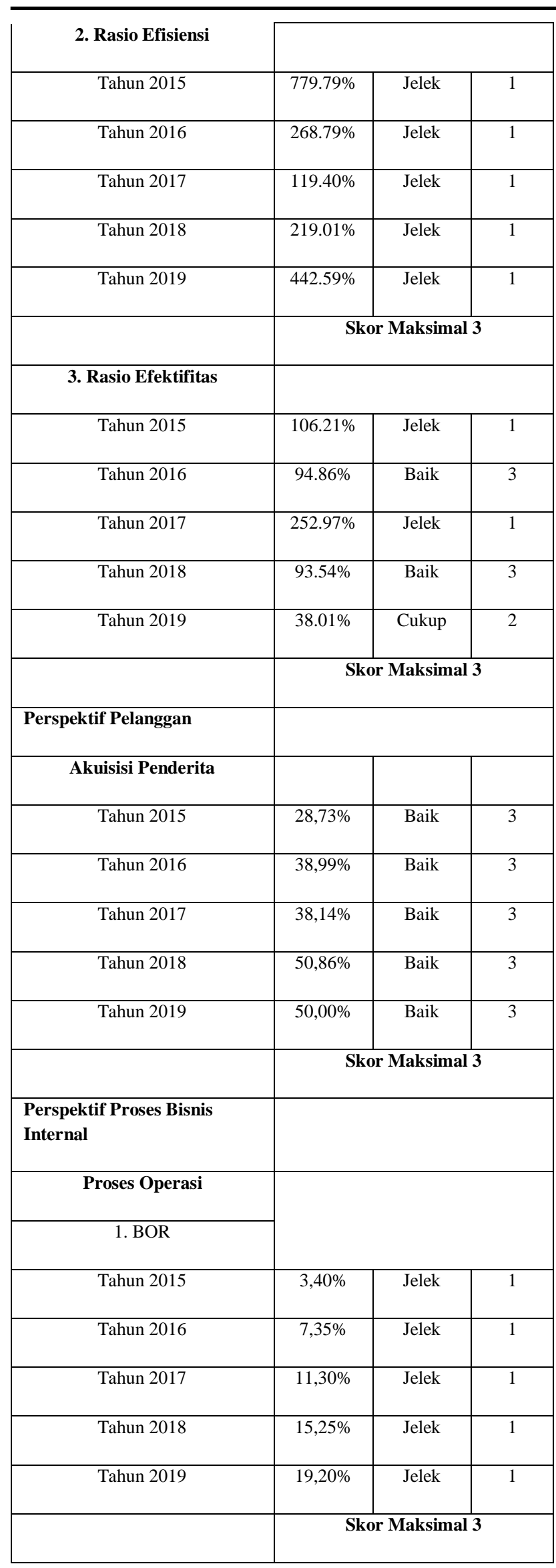

\begin{tabular}{|c|c|c|c|}
\hline 2. BTO & & \multirow[b]{2}{*}{1} \\
\hline Tahun 2015 & $6,08 \%$ & Jelek & \\
\hline Tahun 2016 & $16,25 \%$ & Jelek & 1 \\
\hline Tahun 2017 & $17,25 \%$ & Jelek & 1 \\
\hline Tahun 2018 & $28,41 \%$ & Jelek & 1 \\
\hline Tahun 2019 & $39,58 \%$ & Jelek & 1 \\
\hline & \multicolumn{3}{|c|}{ Skor Maksimal 3} \\
\hline 3. TOI & & & \\
\hline Tahun 2015 & $57,9 \%$ & Jelek & 1 \\
\hline Tahun 2016 & $20,81 \%$ & Jelek & 1 \\
\hline Tahun 2017 & $18,76 \%$ & Jelek & 1 \\
\hline Tahun 2018 & $10,88 \%$ & Jelek & 1 \\
\hline Tahun 2019 & $7,45 \%$ & Jelek & 1 \\
\hline & \multicolumn{3}{|c|}{ Skor Maksimal 3} \\
\hline 4. ALOS & & & \\
\hline Tahun 2015 & $2,04 \%$ & Baik & 3 \\
\hline Tahun 2016 & $1,65 \%$ & Baik & 3 \\
\hline Tahun 2017 & $2,39 \%$ & Baik & 3 \\
\hline Tahun 2018 & $1,95 \%$ & Baik & 3 \\
\hline Tahun 2019 & $1,77 \%$ & Baik & 3 \\
\hline & \multicolumn{3}{|c|}{ Skor Maksimal 3} \\
\hline \multicolumn{4}{|l|}{ 5. GDR } \\
\hline Tahun 2015 & 438,35 & Jelek & 1 \\
\hline Tahun 2016 & 92,30 & Jelek & 1 \\
\hline Tahun 2017 & 57,97 & Cukup & 2 \\
\hline Tahun 2018 & 23,46 & Baik & 3 \\
\hline Tahun 2019 & 12,63 & Baik & 3 \\
\hline & \multicolumn{3}{|c|}{ Skor Maksimal 3} \\
\hline \multicolumn{4}{|l|}{ 6. NDR } \\
\hline Tahun 2015 & 0 & Baik & 3 \\
\hline Tahun 2016 & 0 & Baik & 3 \\
\hline Tahun 2017 & 0 & Baik & 3 \\
\hline
\end{tabular}


Volume 1, Nomor 2, Oktober 2020

\begin{tabular}{|c|c|c|c|}
\hline Tahun 2018 & 0 & Baik & 3 \\
\hline Tahun 2019 & 0 & Baik & 3 \\
\hline & \multicolumn{3}{|c|}{ Skor Maksimal 3} \\
\hline \multicolumn{4}{|l|}{$\begin{array}{l}\text { PerspektifPembelajarandanP } \\
\text { ertumbuhan }\end{array}$} \\
\hline \multicolumn{4}{|l|}{ Produktifitas Karyawan } \\
\hline Tahun 2015 & $\begin{array}{l}5,638,25 \\
1 \%\end{array}$ & Baik & 3 \\
\hline Tahun 2016 & $\begin{array}{l}29,909,9 \\
37 \%\end{array}$ & Baik & 3 \\
\hline Tahun 2017 & $\begin{array}{l}23,616,4 \\
55 \%\end{array}$ & Baik & 3 \\
\hline Tahun 2018 & $\begin{array}{l}26,783,1 \\
10 \%\end{array}$ & Baik & 3 \\
\hline \multirow[t]{2}{*}{ Tahun 2019} & $\begin{array}{l}4,261,07 \\
1 \%\end{array}$ & Baik & 3 \\
\hline & \multicolumn{3}{|c|}{ Skor Maksimal 3} \\
\hline Total Skor & & & 113 \\
\hline
\end{tabular}

Sumber : di olah peneliti

$$
\begin{aligned}
\text { Kinerja } & =\frac{\text { Total skor }}{\text { Skor maksimal }} \times 100 \% \\
& =\frac{113}{165} \times 100 \% \\
& =68 \%
\end{aligned}
$$

Berdasarkan hasil nilai kinerja yang ditetapkan dalam rumus diatas pada UPT. Puskesmas Legung yaitu berada diangka $68 \%$ yang termasuk kategori baik karena berada dikisaran point $60 \%-<80 \%$.

\section{CONCLUSION}

Berlandaskan penjabaran dan diskusi yang menduga diuraikan dalam bab sebelumnya, bahwa bisa disimpulkan bahwa kineja UPT. Puskesmas Legung telah bisa dikatakan baik, bagi makin

jelasnya diuraikan dari tiap perspektif sebagai berkut:

1. Amat-amati atas persepktif financial kemampuan yang dicapai UPT. Puskesmas Legung telah bisa dikatakan sangat jujur, tetapi atas indikator yang difungsikan adalah nalar ekonomis yang membilang realisasi biaya terlihat masih belum digunakan secara maksimal, karena dari tahun 2015 hingga tahun 2019 realisasi anggaran belum ada yang mencapai $100 \%$. Jika ini mampu dipertahankan akan dapat mendanai segala kegiatan yang menunjang pelayanan, sehingga dapat meningkatkan pelayanan dan menarik pelanggan lebih banyak.

2. Dilihat dari perspektif pelanggan bahwa kinerja yang dicapai UPT. Puskesmas Legung yaitu cukup baik, hal ini dilihat dari hasil retensi pelanggan puskesmas dalam mempertahankan pelanggan atau pasien ialah layak baik atas mengalami kegoyahan semasa abad investigasi.

3. Atas prospek proses bisnis internal bahwa kinerja UPT. Puskesmas Legung terlihat dari kinerja pelayanan puskesmas yang dihitung dari kinerja rawat inap yaitu Bed Occupancy Rate (BOR) UPT. Puskesmas Legung rendah. Kenaikan total penderita jaga inap setiap warsa, sehingga pemanfaatan pembaringan menjabat kian minus diiringi penambahan jumlah tempat tidur; Turn Over Internal (TOI) untuk UPT. Puskesmas Legung tergolong tinggi sehingga dapat dikatakan tidak efisien dalam penggunaan tempat tidur puskesmas; Average Length of Stay (ALOS) pada 
UPT. Puskesmas Legung dari tahun 2015 sampai 2019 tergolong tidak ideal, karena rata-rata seorang pasien menginap hanya 1,96 hari. Hal ini menunjukkan bahwa tingkat ALOS (Average Length of Stay) UPT. Puskesmas Legung dibawah standar ideal. Gross Death Rate (GDR) Mutu pelayanan UPT. Puskemas Legung tergolong tidak baik karena angka GDR (Gross Death Rate) tinggi. Oleh karena itu diharapkan pada pihak UPT. Puskesmas Legung mutu pelayanan GDR terhadap pasien lebih ditingkatkan lagi, sehingga mutu pelayanan UPT. Puskesmas Legung mempunyai nilai yang baik dihadapan masyarakat; dan Net Death Rate (NDR) dengan rendahnya angka NDR (Net Death Rate) yang dimiliki UPT. Puskesmas Legung berarti mutu pelayanan UPT. Puskesmas Legung tergolong baik.

4. Hasil dari prospek pembelajaran dan pertumbuhan menunjukkan bahwa kinerja UPT. Puskesmas Legung dari indikator yang digunakan yaitu produktifitas karyawan didapatkan hasil yang masih rendah dari standar yang ditetapkan, jika produktifitas yang diberikan pada karyawan itu kurang akan berpengaruh terhadap kualitas pelayanan yang diberikan kepada pelanggan. Oleh karena itu, kualitas pelayanan yang ada pada UPT. Puskesmas Legung harus ditingkatkan kembali supaya kualitas pelayanan yang diberikan kepada masyarakat akan bisa menarik pelanggan baru terhadap UPT. Puskesmas Legung.

5. Penilaian kinerja UPT. Puskesmas Legung selama 5 tahun dengan menggunakan empat perspektif balanced scorecard sebesar $68 \%$ dan dikategorikan baik.

Berdasarkan hasil penelitian yang diperoleh, maka saran yang dapat disampaikan oleh penulis kepada UPT. Puskesmas Legung ialah sebagai berikut:

1. Bagi Akademisi

Bagi akademisi kemudian disarankan bagi melaksanakan peneliti atas dua objek berdasar bagi bisa dibadingkan dan memakai abad yang lebh jauh bagi bisa lebih menggambarkan objek penelitian.

2. Bagi Pihak UPT. Puskesmas Legung

a. Perpektif financial, agar pihak puskesmas mengoptimalkan biaya yang telah diberikan.

b. Prospek konsumen, disarankan bagi lebih meluaskan derajat bantuan supaya bisa lebih menarik konsumen.

c. Pespektif porses bisnis internal, kinerja bantuan kurang bagus sehingga lebih ditingkatkan untuk lebih memberikan kenyamanan dan kepuasan konsumen.

Perspektif pembelajaran dan pertumbuhan, perlunya dilakukan peningkatan jumlah karyawan yang mengikuti pelatihan, hal ini

\section{REFERENCES}

Ariyanto, F. D., Sri, M., \& Topowijono. (2016). Penerapan Balanced Scorecard Sebagai Tolok Ukur Kinerja Perusahaan ( Study pada PT . Marinal Indoprima ). Jurnal Administrasi Bisnis, 39(1), 5864.

Mahsina, M., Poniwatie, A., \& Cholifah, C. (2017). ANALISIS PENERAPAN 
Volume 1, Nomor 2, Oktober 2020

BALANCE SCORECARD, ALAT UKUR PENILAIAN KINERJA PADA DINAS PENDAPATAN, PENGELOLAAN KEUANGAN, DAN ASET KABUPATEN SIDOARJO. Jurnal Maksipreneur: Manajemen, Koperasi, Dan Entrepreneurship, 7(1), 59.

https://doi.org/10.30588/jmp.v7i1.323

Manajemen, D., Ekonomi, F., \& Manajemen, D. (2016). Perancangan Balanced Scorecard sebagai Pengukuran Kinerja pada PT Asuransi MSIG Indonesia Ramadhani Erlin Trisyulianti. Ramadhani.
Parmita, R. (2019). Pendekatan Balanced Scorecard Pada Rumah Sakit. 143-153.

Riyana, D. H. (2017). Pengukuran Kinerja Perusahaan Pt Indofood Dengan Menggunakan Balanced Scorecard. Jurnal Sekuritas, 11(22), 42-53.

Sujarweni, Wiratna. 2015.Akuntansi Manajemen.Yogyakarta:Pustaka Baru Press

Sa'adah, Lailatus. 2018. Balanced Scorecard. Yogyakarta: CV BUDI UTAMA 